\section{HINTS FOR NATURE-STUDY.'}

(I) $\mathrm{M}$ RS. BRIGHTWEN was one of the pioneers $M$ in the art of making young people acquainted in a pleasant way with the plants and animals round about them, and we wish to express our opinion that the mood and method of much of the "Nature-Study" which has been hurriedly set a-going in schools to-day is right or wrong just as it agrees or differs from what we find in the simple and homely studies by the author of "Wild Nature Won by Kindness." We say this very deliberately, although, to tell the truth, there is not much in the particular book before us, which must be treated tenderly, as its title suggests, and for the sake of what has gone before. But even here we find some of the qualities which distinguish sound naturestudy-fidelity to observed fact, appreciation of the wonder and beauty of common things, and insistence on interpretation rather than information. The book shows how problems of a simple sort may be solved in simple ways, given patience and a window-sill.

(2) We have also before us a beautiful popular edition of Mr. R. Kearton's "Adventures of Cock Robin and his Mate "-a book for boys and girls, which first appeared in Ig04, and has been deservedly popular. The photographic illustrations have never been excelled, and there is plenty of sound natural history in the often rather quaint colloquy between the cock robin and his precocious chicks, who persist in asking about migration and that sort of thing. We wish to record-for what it is worth-the opinion of some young readers that they like to listen to Mr. Kearton and to the robin, but not to the two at once.

(3) Mr. Snell apologises for his study of the common objects of the country, but there is no need for apology. His unpretentious descriptions are direct and appreciative, his photographic illustrations are

${ }^{1}$ (I) "Last Hours with Nature." By Eliza Brightwen. Edited by W. H. Chesson. Pp. 223; illustrated. (London: T. Fisher Unwin, 1908.) Price $2 s .6 \pi$. net.

(2) "The Adventures of Cock Robin and his Mate." By R. Kearton. With upwards of $\mathrm{r}$ ro illustrations from photographs taken direct from nature by Cherry and Richard Kearton. Pp. xvit240. (London: Cassell nature by Cherry and Richard Kear

and Co., Ltd., rgo8.) Price $3 s .6 d$. (3) "Nature Studies by Night and Day." By F. C.
illustrated. (London: T. Fisher Unwin, ryo8.) Price 5 s.

(4) "The Nature-Book. I. A Popular Description by Pen and Camera of the Delights and Beauties of the Open Air." Pp. iv +372 ; 13 plates, of the Delights and Beauties of the Open Air." Pp. Iv+ 372 ; 13 plates, 12 coloured, and numero

1908.) "Price $12 s$. net.
(5) "The Story of the Sea and Seashore." By W. Percival Westell. Pp. 343; illustrations from photographs and drawings (the latter mostly by C. F. Newall) and 8 coloured plates ( 7 by W. S. Berridge and $x$ by C. F. Newall), (London: Robert Culley, n.d.) Price 5s. net. (6) "The House in the Water; a Book of Animal Life." By Charles G. D. Roberts. Pp. 323 ; with 18 full-page plates. (London: Ward, Lock and Co., I.td., r908.) Price $6 s$.

(7) "Close to Nature's Heart." By William M'Conachie. Pp. $x+276$. (Edinburgh and London: William Blackwood and Sons, rgo8.) beautiful and with ideas behind them, and the whole book has an open-air feeling about it. In connection with "Nature-Study" in schools, this book will be of service in showing the beauty and interest of common things. Mr. Snell begins with a study of the so-called sleep of plants, and shows us anemones and wood-sorrel and goatsbeard open and closed, and the sweet-scented evening campion conspicuous in the dim light. Another study deals with protective coloration, and is illustrated, for instance, by admirable photographs of the eggs of the ringed plover among the stones on the beach, and of the lappet-moth, so like a crumpled, withered leaf. The author has an interesting note on the way animals squat in conspicuous places when they are away from their usual surroundings, and he doubts if birds often catch butterflies in flight; but this useful scepticism might have been extended with advantage to some of the author's own sentences, e.g. that which points out the boulder-like appearance of the "half-wild mountain sheep " of Wales and Scotland. Are these the moutons sauvages which the French visitor slew

$$
\text { No. } 2057 \text {, VOL. 80] }
$$


whole. The book gives useful samples of profitable nature-studies, e.g. of a river or of a wasp nest, but more should have been made of the remarkably fine collection of illustrations. We may also point out that there is an unpleasant smack in some of the much too ambitious titles-" How to know the Insects," and so on.

(5) Mr. Westell's guide to the natural history of the sea and seashore contains much interesting information, somewhat carelessly stated, and many of the illustrations are very fine. In many cases the coloured plates do not show the natural colours, and the text contains many errors. It is a pity to speak of the "bones of starfish," of the Bass Rock as a "remarkable headland," of Luidia as "one of the largest British brittle-stars," of Polycystina as "shell-fish." Mr. Westell refers frequently and gratefully to Miss Newbigin's admirable "Life by the Seashore," but the fact that he never spells her name correctly is a trivial illustration of the carelessness which disfigures his book. well done. But that there is something more than all this a book like Mr. M"Conachie's reminds us, for it expresses an end of nature-study which, if attained, covers a multitude of sins, but without which the naturalist with his lynx eye is a fingering slave, and the school garden only an open-air laboratory. That end is the love of the country, which is to be felt, not spoken about. Mr. $M^{\prime}$ Conachie does not speak of it, except, perhaps, in the repellent title of his book, which is congruent, however, with his vocation, but his pictures, which are worthy of a place beside those of Jefferies and Burroughs, reveal it eloquently. He knows his birds and his flowers not as species so much as familiar friends; he takes us, not on botanical excursions, but for a walk in the country, and we return wondering whether it was poet or naturalist who led us. Nur was du fühlst das ist dein Eigenthum, and no one can read these sketches-such as the coming of spring, the promise of summer, the turn of the year, and December days-without feeling that the author has made the natural history of the year his own in the truest sense. Many of the sketches are local; but though we have never been very near the Scotch parish w h i c h contains the quarry pool, the brook path, the mill stream, the haunt of the pike, and the old forest that we now know, there is so much of the universal in the pictures that we seem to have known and loved them for many years. To all who would know the true inwardness of nature-study we commend this book. J. A. T.

\section{LIEUT. SHACKLETON'S ANTARCTIC EXPEDITION.}

(I) Explorations and Results.

Canadian animals, and tells a good story. There is convincing work in his nature-studies, and "From the Teeth of the Tide" is uncommonly well done. It is unlikely that the author meant his tales to be included under the serious rubric of " nature-study," but they may help some to get away from the fallacious automatic-machine theory of the creature.

(7) What are the ends of nature-study, for they are many? We are told that this discipline-which is now part of the day's work of the elementary school- "implies an appreciative outlook upon the whole environment, and that not from a scientific view-point only, but from the æesthetic and practical as well." Thus among the aids to nature-study which have sprung up on demand with almost magical quickness, some emphasise precise observation and others graphic registering; some the cultivation of the school garden, and others the culture of the scientific mood; and all this is well if it be
THE anxiety occasioned by the delay in the return of Lieut. Shackleton's expedition has been relieved by its safe arrival and the news of its supreme success. A cable published in the Daily Mail of March 24 records the magnificent exploits of the expedition, and though there are occasional obvious verbal inaccuracies in regard to some technical points, the report makes clear the main outlines of its great achievements. They unquestionably place it in the front rank of Polar expeditions. Its two most striking achievements were the sledge journeys by which Lieut. Shackleton reached within one hundred geographical miles of the South Pole, and discovered the nature of the very centre of the South Polar region, and by which Prof. David gained the magnetic south pole, and rendered almost certain the continuity of South Victoria Land and Wilkes Land.

The expedition was landed early in 1908 near the
NO. 2057, VOL. 80] 